\title{
Resenha
}

\section{Quando a política caminha na escuridão: interesse e virtude n'A democracia na América de Tocqueville}

NICOLETE, Roberta Soromenho. São Paulo: Alameda, 2018.

Luís Alves Falcão ${ }^{1}$

Há pensadores políticos que podem facilmente ser classificados de acordo com a doutrina, ideologia ou linguagem, ainda que se negue, corretamente, qualquer rigidez em enquadramentos imutáveis ou demasiadamente rígidos. Todavia, há também aqueles cujos especialistas penam por alguma classificação; tornam-se, pois, matéria de infindáveis querelas e, de tempos em tempos, há sempre quem os enquadre em novos e heterodoxos parâmetros. Por isso, no geral, a confrontação classificatória é recorrentemente feita e refeita. Foi-se época em que Maquiavel era um conselheiro de tiranos, Locke apenas um liberal, Rousseau um carbonário; hoje, Hobbes é um proto-liberal, Marx é um defensor de minorias, Mill, um conservador, e Schumpeter, um elitista a despeito de qualquer democracia.

Ao falar de democracia, aliás, é quando se suscitam as mais diversas paixões. Talvez porque, por milênios, foi duramente criticada, e, hoje, seria impensável, para qualquer um que queira ser ouvido, negá-la. Essa mancha cinzenta, para repetir o incansável Bobbio, forjada nos fins do Antigo Regime apontou, desde o início, a contradição inerente entre soberania popular e governo representativo. Atacar a questão democrática pela via estrita de princípios universais ou de instituições só fez reafirmar a contradição. Uma estratégia mais inteligente é escavar nos escombros das sociedades aristocráticas, para já seguir a autora resenhada, o que sobrou e o que foi destruído. A democracia era o futuro, que não é mais o mesmo dos meados do século

\footnotetext{
${ }^{1}$ Professor no Departamento de Ciência Política Universidade Federal Fluminense (UFF).
} 
XIX. É necessário, pois, uma sociologia fina, desafiadora de um contratualismo rousseauniano prospectivo, de uma máxima de Montesquieu sobre a impossibilidade de repúblicas viáveis em grandes países, de uma dicotomia atroz de duas liberdades de Constant ou de um progresso civilizacional de Guizot. Aprendendo com seus mestres, e escrevendo em parte contra eles, como bem the ensinou Madison, Tocqueville se recusa a ser uma dessas coisas, mas não nega a inspiração em todas elas.

Alexis de Tocqueville é caso raro na história do pensamento político, particularmente entre os clássicos, pois não é, de tempos em tempos, revisitado para novo enquadramento interpretativo, é, ao invés disso, em todos os tempos visitado com diferentes classificações. Tocqueville já foi e continua sendo conservador, liberal, republicano; biograficamente aristocrata, ideologicamente democrata, e vice-versa. Lido pelas miudezas de sua escrita, pelas aventuras de sua vida, pela sombra da Revolução, pelo contexto e linguagem na qual estava inserido, o francês foi e continua sendo aquele que embute sociologicamente os costumes e os sentimentos no que tradicionalmente era tratado como instituições jurídicas, como as formas de governo, por exemplo. A tensão entre aristocracia e democracia, com as contradições que thes são devidas, expressam, na letra do escritor, costumes e sentimentos de um novo mundo que se abre. Nesse mundo de escuridão, entre o abismo do passado e a incerteza do futuro, Tocqueville reflete com ancoragens próprias de linguagens outras que não a da aristocracia ou democracia. A virtude e o interesse passam a ser, depois dele, termos centrais dos regimes que se anunciam e que, até então, eram relacionados à república ou ao liberalismo. Daí se entende, portanto, as causas de tantos Tocquevilles.

Roberta Soromenho Nicolete se recusa a fechar uma questão de qual seja o Tocqueville verdadeiro. Antes, enfrentando competentemente a dificuldade desse tipo de trabalho, escava, na dimensão autoral do escritor e sem descuidar do controle histórico - diga-se -, as possíveis soluções dessa equação tocquevilleana muito mal resolvida. A ascensão da linguagem do interesse parece se contradizer com a democracia, em seus moldes clássicos, mas está diretamente relacionada a esse novo 
mundo igualitário. Como, então, se relaciona o interesse privado com a virtude pública? A propósito, a questão foi abordada de muitas maneiras: da solução ciceroniana de coadunar utilidade individual com a pública àquela da economia política moderna da resultante pública virtuosa de um conjunto de vícios privados. Tocqueville não se contenta com nenhuma delas. Seu segredo? A manutenção das liberdades em sociedades democráticas está em xeque, uma vez que, começado o processo de equalização das condições, não se pode pará-lo e isso é perfeitamente observável no Novo Mundo, mas que, cedo ou tarde, chegará a todo o Ocidente. Um dos méritos fundamentais do trabalho de Roberta Nicolete é o de buscar na teoria não a classificação de o que seja o Tocqueville, mas usá-lo a fim de compreender, e quiçá responder, a questão que ainda hoje nos faz perder o sono. Como equacionar interesses e virtudes no mundo democrático?

O conceito fundamental que conduz o esmerado trabalho de Roberta Nicolete, o interesse bem compreendido, desloca o confronto Cícero - Adam Smith para uma dimensão inteiramente nova. No capítulo VIII do segundo volume de $A$ democracia na América, Tocqueville confronta o leitor com a ascensão de uma nova sociedade com valores da velha aristocracia, como é típico de sua escrita. Mas ali, revela ele, as doutrinas dos moralistas passam a ser generalizadas quando o interesse particular e o interesse geral se coadunam de tal modo que se torna impossível diferenciá-los. O que opera a unidade de dois polos tradicionalmente opostos? Para responder à questão, Roberta Nicolete necessita esmiuçar as fontes da igualdade.

Engana-se o leitor que acreditar que a Introdução do livro, repleta de referências diversas ao contexto intelectual de Tocqueville, reduziria o trabalho à exegese eruditamente contextualista. Pelo contrário, a análise do surgimento da preocupação em torno do individualismo coloca o autor estudado em perspectiva e justifica, assim, como responder a um Tocqueville. Um Tocqueville que reflete sobre aquilo que lhe está posto, mas também que segue na linha tênue entre a descrição e a normatividade, como salienta Roberta Nicolete muito precisamente. Retomando a questão, lemos:

Seria o novo estado social, ele próprio, uma grande depressão a qual estariam lançados homens e mulheres, uma vez ameaçados pela tirania da maioria? E em meio a tanto pó, ruínas, fúria e terror, como preservar a 
liberdade, fazendo desse regime de igualdade um regime justo? Isto é, aquele no qual os homens não são iguais na escravidão, mas no qual a liberdade se associa à igualdade. (p. 22)

Tal ponto já havia se colocado, pelo menos, desde Montesquieu, para ficarmos no universo francófono. O que há de comum entre despotismo e republicanismo, particularmente em repúblicas democráticas, é justamente o fato de que são regimes igualitários, a se diferenciarem da monarquia, que, por preservar as desigualdades, garante a liberdade. A república, sobretudo a democrática, mas também a aristocrática, é o único regime que une liberdade e igualdade, e isso Tocqueville observou na democracia americana. Cabe questionar, então, qual seria a natureza de um "regime justo" da formulação da autora, uma vez que na esteira de Montesquieu e Constant, Tocqueville preza o tema da justiça como um desenvolvimento moral de pequenas nações (Democracia na América, Terceira parte, capítulo V). O novo estado social não é aquele que finda, mas que recoloca a questão sempre tensa entre igualdade e liberdade, conduzindo à reflexão de um regime legítimo.

A associação entre liberdade e igualdade, aliás, traça o paroxismo de uma vida social que, porque igualitária, individualista. Talvez seja este um dos motes mais estudados na obra tocquevilleana, as condições que levam à igualdade americana são as mesmas que levam ao isolamento, as mesmas que distanciam os cidadãos das virtudes dos antigos: o patriotismo, a glória, a abnegação de si e a dedicação desinteressada ao bem público. Ainda que tais características sejam - como eram nos tempos de Tocqueville - essencialmente romantizadas, Roberta Nicolete nos faz observar que, do auge intelectual do século XVIII à geração de Tocqueville, tais valores não se perderam como referências primordiais para a ação política. Talvez, nesse ponto, caiba uma observação. Não obstante a competência com a qual a autora reconstrói os termos teóricos dos muitos significados de interesse - particularmente nas seções "As paixões versus os interesses" e "Os interesses e as virtudes" do capítulo 2 -, o texto ganharia, se dedicasse mais tinta às relações com a doutrina exposta por Tocqueville. Tal observação, deve-se firmar, não depõe contra o texto, apenas ratifica 
a linha tênue à qual o leitor está exposto entre o ambiente intelectual e os particularismos tocquevilleanos. A autora provou, no ponto alto de seu argumento, na seção "A doutrina do interesse bem compreendido" do capítulo 2, que as possíveis correspondências conceituais entre Tocqueville e seus antecessores são absolutamente frutíferas para este tipo de estudo.

Ainda sobre os particularismos, remontamos à frase: "Do individualismo e da paixão principal na democracia, a paixão pela igualdade, é possível entrever traços virtuosos, como a doutrina do interesse bem compreendido e a perseguição, menos obstinada, mas aguerrida, da liberdade" (p. 25). Parece ser este o ponto nefrálgico da obra resenhada. Roberta Nicolete escapa, como apontamos acima, da dicotomia entre uma rememoração romantizada e, talvez, fictícia das virtudes dos antigos e a ascensão de uma interpretação da atividade política como um mercado. Enganam-se também aqueles que julgam ser o interesse bem compreendido um ponto médio entre a virtude ciceroniana e os vícios privados do capitalismo. Não se trata de uma composição dessas coisas, também não se trata de uma contraposição entre virtude e vício; trata-se de um ponto comum entre interesses públicos e privados que, sim, acaba por não distinguir virtude de individualismo, a partir de sobreposições de linguagens de diversas matrizes, como muito precisamente aponta a autora.

Mas a questão de fundo ainda permanece: o que significa, afinal, afirmar que o interesse bem compreendido seja o elemento essencial das sociedades democráticas capaz de unir virtude e interesse?

Contudo, a nossa hipótese é a de que, como tudo que dizia respeito ao novo
estado social de igualdade de condições (tal estado, na verdade, a
preocupação central do autor), a investigação da relação entre virtude e os
interesses foi fundamental para Tocqueville compreender a teoria moral
com a ajuda da qual os estadunidenses ludibriavam o tempo e continham a
fatal e necessária corrupção das constituições políticas (p. 30-31).

Ao limpar o campo de estudos na recusa de que o interesse bem compreendido seja razão ou educação formal, a autora o entrelaça ao costume, "pois ele associará virtude e interesse, escapando do simplismo redutor que divide a liberdade entre antigos e modernos" (p. 33).

Depois de debater as causas que levaram Tocqueville a deixar a França e visitar a América, o livro segue, ainda no capítulo 1, abordando os impactos causados 
na mente do escritor, que se revelariam ainda mais incisivos ao designar "democracia" como um "estado social" (p. 41). Um ponto a ser destacado nessa altura do argumento reside na percepção tocquevilleana de que as causas iniciais, a origem da igualdade de condições, não o levariam muito longe, sendo necessário, antes, remontar a questão ao seu sentido e orientação. Tal proposição poderia deslocar um Tocqueville da posição de filósofo político, cuja normatividade residiria na doutrina do interesse bem compreendido, para um que antecipasse positivamente uma história futura. Para unir as duas pontas, de uma sociologia política do novo mundo e de um sentido para todo o Ocidente, seria interessante um comentário sobre as possíveis recepções e indagações tocquevilleanas a respeito da filosofia da história e do progresso humano. Ou ainda, para indagar, com o espírito do século, o que é moralmente desejável é também positivamente inevitável? Ainda que se sabia, e isso não se pode perder de vista, das reticências tocquevilleanas a respeito da democracia, o interesse bem compreendido seria uma resposta plausível para tais receios.

Em poucas palavras, ainda que seja o curso igualitário irrefreável, os homens podem conduzi-lo e, mediante artifícios, aplicar uma forma à sociedade. É preciso, então, ter em vistas o momento de seu nascimento, seu ato fundacional, para acompanhar os primeiros passos desse princípio de igualdade que, com o tempo, tomará a fisionomia do estado social e político estadunidense. (p. 51)

$\mathrm{O}$ ato fundacional pode ser visto, assim, como o elemento que aproxima e distancia Tocqueville do republicanismo. Se o tema da fundação percorre toda a tradição republicana, não o faz, do ponto de vista teórico, do mesmo modo do de Tocqueville. Assunto debatido de Maquiavel a Rousseau, para citarmos apenas duas pontas importantes do percurso, ele pode ser interpretado em Tocqueville como a experiência empírica da criação norte-americana, para repetirmos Gordon Wood. Compreende-se, desse modo, a construção paulatina de uma obra, recheada de detalhes, de aspectos físicos do território, da interação comercial, dos valores morais e religiosos, das artes e ciências, da produção pública da opinião. Essa construção sociologicamente orientada pode ser vista como o substitutivo lógico de uma ação fundacional, heroica e individual. 
A análise desse ponto se encontra na seção "Depois do combate, o legislador". As associações civis desempenham papel fundamental para o entrelaçamento entre igualdade de condições e individualismo. Justamente pelo fato de os interesses se sobreporem, nas democracias, às virtudes, os homens se associam com fins particulares, mas é a reunião desses diferentes individualismos que compõe a reconfiguração de um sentimento de coletividade, ainda que local ou pontual. A dimensão inventiva e inovadora desse artifício, dessa "arte humana" (p. 64), repousa suavemente sobre a força do legislador em impor forma à matéria. Esse nexo argumentativo de Roberta Nicolete, da igualdade de condições à função do legislador, passando pelo individualismo e associativismo, é construído com bastante esmero e fina sagacidade a partir da obra de Tocqueville. Mas talvez ganhasse em conteúdo se a figura do legislador fosse mais esmiuçada, a fim de não confundi-la, como podem imaginar leitores mais desavisados, com um Rousseau.

Já no capítulo 2, encontramos o efetivo florescimento do trabalho, amadurecido pelas páginas anteriores. De saída, após introduzir a problemática, a autora classifica as diferentes "Doutrinas do interesse", título da primeira seção, em três: egoísmo esclarecido, utilidade e dever. A quarta, a do interesse bem compreendido, é "contrastante com as anteriores, que faz o homem aprender a viver no presente, pois a realização de seus interesses está na terra" (p. 79). É explicado, assim, ao leitor o devido lugar do que se trata, afinal, da doutrina alardeada por Tocqueville e, desse modo, faz eco à seção seguinte. Nela, discute-se o percurso, evocando Albert Hirschman e Pierre Force, do conceito de interesse na modernidade. A contraposição à razão merece destaque, uma vez observado o tema da razão de estado, via Maquiavel, e o complexo emaranhado conceitual de Harrington, no qual ele conclui que não há interesse que não seja genuíno e, portanto, claro apenas ao indivíduo portador dele. Nesse ponto, é interessante notar que ambos os termos são estranhos ao pensamento tocquevilleano, que, em leituras precipitadas, poderiam supor desacordo de fundo valorativo entre o interesse dos seiscentos inglês e o interesse propriamente compreendido, como justificado na sequência do livro. Também não foi a ascensão da sociedade comercial a responsável por coadunar interesse e virtude, pois, na mesma geração de Rousseau, Holbach apresentava sua 
reticência para com a alardeada virtude dos antigos em descompasso com a naturalidade do interesse humano.

Chegamos assim ao ponto alto do livro. Na seção "A doutrina do interesse bem compreendido", o diálogo com os comentadores aumenta e, com isso, delineia-se com precisão a originalidade da contribuição de Roberta Nicolete. A autora aprecia minuciosamente, com o rigor que lhe é particular no trato com as palavras, os significados semânticos de "interesse bem compreendido". Debate com traduções e tradutores, não por erudição petulante, mas por ser, justificadamente, o entendimento conceitual estreitamente dependente do vocabulário. "Nessa leitura, compreender bem um interesse é a ação na qual se perscruta e em que consiste a busca de interesses e necessidades individuais quando confrontados com os comuns" (p. 98). E é a partir de tal ação que, não voltada exclusivamente para si mesmo, mas para o coletivo, agem os homens democráticos, ainda capazes de razoabilidade. Ainda que essa interpretação pudesse aproximar Tocqueville do republicanismo de um Skinner - quando interpreta a irracionalidade da ação corrupta -, o argumento caminha para um "campo moral associado a um ponto fixo [...]: o interesse" (p. 100), que opera como substitutivo da virtude antiga ou aristocrata.

É digno de destaque o paralelo feito, a partir daí, entre o interesse bem compreendido de Tocqueville e o Manuscrito de Genebra, de Rousseau, menos porque mostra as proximidades, e mais porque apresenta os limites comparativos. Embora não com essas palavras, os limites revelam por baixo que as proposições rousseanianas universalistas da natureza humana - com todo peso que seu jusnaturalismo carrega não podem ser condizentes aos estadunidenses. Na verdade, não são condizentes com a perspectiva sociológica da tradição à qual Tocqueville se filia, do estudo in loco de um punhado virtualmente infinito de características sociais e políticas que empurra uma nação para determinada direção. Essa perspectiva, por outro lado, se une à de Rousseau pelo patriotismo, aliás, tema comum de algumas leituras republicanas.

O debate que se segue gira em torno da utilidade do interesse bem compreendido, através dos costumes e, fundamentalmente, da religião. Roberta 
Nicolete lembra que essa doutrina se separa com veemência do utilitarismo de Bentham, já que esta dispensa qualquer moralidade e supõe a naturalidade do individualismo isolado. Com isso, chegamos ao momento conclusivo da obra. A interpretação da autora viabiliza uma leitura de que o interesse bem compreendido é capaz de conduzir os homens à "perfectibilidade humana", uma vez que "a doutrina do interesse não versa sobre o interesse mesmo, sobre o objeto do desejo, mas sobre como as disposições são criadas pelos costumes" (p. 114). Mas é preciso ter cautela na medida em que as instituições americanas não podem acriticamente ser transportadas para qualquer país que avança, ou padece, no progresso das condições de igualdade. Os Estados Unidos não são o futuro da França, porém, apontam os problemas para o Velho Continente. O verdadeiro ponto de inflexão de Tocqueville, assim, é que "a partir de então não seria mais possível postular a virtude senão associada ao interesse" (p. 117).

A conclusão explora o percurso da recepção da obra tocquevilleana, suas diferentes interpretações, as justificativas para se ler e reler, sempre, Tocqueville, ainda mais com a ascensão das democracias contemporâneas depois da Segunda Guerra, que continua a nos apresentar a contrariedade inerente do governo representativo com a soberania popular. E tudo isso, sem descuidar de toda a poesia que o autor de A democracia na América e a autora de Quando a política caminha na escuridão brindam o leitor com a elegância da escrita que une Tocqueville e Roberta. 